\title{
Ecos no jardim de YHWH Seis novas relações intertextuais entre Gn 2-3 e Nm 22-24
}

Teresa Akil

\section{Introdução}

"A intertextualidade também, abre janelas para outros textos e providencia espelhos que refletem estruturas textuais"

Dentre os eficazes instrumentos pedagógicos utilizados para o desenvolvimento infantil estão os contos fabulosos, sempre permeados por manifestações oníricas intrínsecas ao imaginário humano e por desfechos morais exemplares.

Alguns autores da Sagrada Escritura, explorando esse caráter pedagógico, também utilizam os contos fabulosos a fim de que leitores de todas as épocas e idades pudessem aprender mensagens morais ad eternun.

Dois contos fabulosos são especialmente marcantes no Antigo Testamento: a história de Eva e a Serpente (Gn 3,1-6) e a história de Balaão e sua mula (Nm 22,22-35). Por mais insipiente que seja o conhecimento do leitor sobre os "assuntos da Escritura", pelo menos essas duas histórias são de conhecimento público e notório.

$\mathrm{Na}$ Academia, entre professores e alunos, muitas foram às linhas escritas sobre as passagens, nos seus diversos aspectos. Nos anos 90, partindo da

\footnotetext{
${ }^{1}$ GRAHAM, Susan, Intertextual Trekking: Visiting the iniquity of Fathers Upon the Next Generation" Semeia 69/70 - Intertextuality and the Bible, January, 1995, p. 197.
} 
leitura intertextual da Bíblia, G. Savran produziu um excelente estudo sobre as relações intertextuais entre Gn 2-3 e Nm 22-242.

Tendo como ponto de partida o trabalho de Savran, este artigo se propõe ampliar as relações intertextuais entre as histórias de Gn 2-3 e Nm 2224. A partir de elementos inerentes a textualidade ${ }^{3}$, este artigo fará uma leitura comparativa de dois ou mais textos. Serão apontadas novas semelhanças e diferenças e serão elencados, comparativamente, mais alguns temas, aspectos dos personagens, palavras (paralelos léxicos), seqüência narrativa e conceitos/motivos teológicos.

\section{Um pouco de teoria intertextual}

O termo intertextualidade foi cunhado pela primeira vez pela crítica literária francesa Julia Kristeva em 1969, quando esta repensava as teorias e conceitos sobre diagolismo de Mikail Bahktin ${ }^{4}$.

Para Kristeva um texto é "um conjunto de enunciados, tomados de outros textos, que se cruzam e se relacionam" ou que "todo texto se constrói como mosaico de citações, todo texto é uma retomada de outros textos. Na apropriação pode-se dar desde a simples vinculação a um gênero, até a retomada explicita de um determinado texto"

Essa concepção de texto como "mosaico de citações" acarreta a infinita reinvenção e repetição de formas e conteúdos, uma rede interminável em que diferentes seqüências transformam-se em outras seqüências, (re)utilizando de incontáveis maneiras os materiais textuais existentes ${ }^{6}$.

${ }^{2}$ SAVRAN, G., "Beastly Speech: Intertextualy, Ballam's Ass and the Garden of Eden". Journal of the Study of the Old Testament, Jerusalem, n. 64, p. 1-40, 1994.

${ }^{3}$ Por elementos inerentes à textualidade entende-se "quando de dois textos faz-se uma referência cruzada, elaborando um index de palavras repetidas, conceitos e motivos teológicos". Conf. PENHANSKY, David, Staying the Nigth: Intertextuality in Genesis and Judges. In: FEWELL, Danna Nolan (ed.), Reading Between Texis: Intertextuality and the Hebrew Bible (Literary Currentsin biblical Interpretation), Louisville: Westminster/John Knox Press, 1992, p. 78 .

${ }^{4}$ ORR, Mary, Intertextuality: Debates and Contexts, Cambridge, Polity, Press, 2003, p. 20; ALLEN, Ghaham, Intertextuality (The New Critical Idiom), London, Routledge, 2000, p. 39; VIGNER, Gerard, Intertextuality, norma e legibilidade In: GALVES, Charlotte; ORLANDI, Eni P. \& OTONI, Paulo, O texto, leitura e escrita, Campinas, Pontes, 1997, p. 32.

${ }^{5}$ KRISTEVA, Julia, Introdução à semanálise, trad. Lúcia Helena França Ferraz, São Paulo, Perspectiva, 2005, p. 68.

${ }^{6}$ CACHERO, Antonio Pineda, Comunicación y intertextualidad en El cuarto de atrás, de Carmen Martin Gaite ( $1^{\mathrm{a}}$ parte): Literatura versus propaganda, Revista Especulo, Madri, n. ${ }^{\mathrm{o}}$ 16, nov.2000/fev.2001, Disponível em:

http://www.ucm.es/info/especulo/numero16/pineda1.html, acesso em 16 ago.2006 ao referirse à intertextualidade na obra El cuarto de atrás, de Carmen Martin Gaite, diz: "Textos sobre 
Já a inserção de elementos dentro do texto, constrói uma rede dialógica da escritura-leitura: "Um texto estranho entra na rede da escritura: esta o absorve segundo leis específicas que estão por descobrir. Assim no programa de um texto, funcionam todos os textos do espaço lido pelo escritor ${ }^{7}$ ".

Para essa crítica francesa a intertextualidade é um fenômeno que se encontra na base do próprio texto literário, imbricada com sua inserção num múltiplo conjunto de práticas sociais relevantes. A partir de Kristeva, "texto" passa a ser entendido como o evento situado na história e na sociedade, que não apenas reflete uma situação, mas é essa própria situação. "Pelo seu modo de escrever, lendo o corpus literário anterior ou sincrônico, o autor vive na história, e a sociedade se escreve no texto" ${ }^{\text {. }}$.

É nessa percepção de que um texto pode ser aludido por outro, que se pode ler as histórias de Eva e da Serpente (Gn 3,1-6) e de Balaão e sua mula (Nm 22,22-35).

\section{As semelhanças entre Gn 2-3 e Nm 22-24}

O estudioso Savran G. no seu artigo "Beastly Speech: Intertextualy, Ballam's Ass and the Garden of Éden" ("O discurso das bestas: Intertextualidade, a mula de Balaão e o Jardim de Éden") aponta várias alusões entre os textos de Gn 3,1-6 e Nm 22,22-35. Assim, começa dizendo que essas passagens são os dois únicos casos bíblicos onde animais conversam com pessoas. Exatamente por isso é possível traçar semelhanças entre os episódios da mula falante de $\mathrm{Nm} 22,22-35$ e o da serpente falante de Gn 3,1-59.

A primeira semelhança apontada pelo autor está na compreensão final das passagens de Gn 2-3 e Nm 22-24. Em outras palavras, para que o leitor compreenda com eficácia a mensagem das passagens, é necessário que entenda o que se passa no diálogo entre homens e animais, a parte mais importante dos respectivos blocos ${ }^{10}$.

A segunda semelhança é quanto à introdução dos textos: em ambos é o animal que, com desenvoltura, dirige a palavra ao ser humano (Gn 3,1 e $\mathrm{Nm} 22,28)$ e inicia uma conversa que gira em torno de uma proibição de YHWH - no caso de Gn a proibição de ser comer do fruto da árvore do bem

textos, textos dentro de textos, textos que condicionan y configuran la lectura de otros textos y que n última instancia, determinan el mundo de la protagonista".

${ }^{7}$ KRISTEVA, Julia, Introdução à semanálise, trad. Lúcia Helena França Ferraz, São Paulo, Perspectiva, 1974, p. 98.

${ }^{8}$ KRISTEVA, Julia, Introdução à semanálise, trad. Lúcia Helena França Ferraz, São Paulo, Perspectiva, 1974, p. 98.

${ }^{9}$ SAVRAN, G., op. cit., p. 33-36.

${ }^{10}$ SAVRAN, G., op. cit., p.34. 
e do mal (Gn 2,16-17) e em Nm Balaão ir ao encontro de Balaque (Nm $22,22)^{11}$.

A terceira semelhança apontada por Savran é o fato das passagens não explicarem como animais podem falar com tanta habilidade e da falta de estranheza dos personagens humanas, que naturalmente conversam com os animais $^{12}$.

A quarta semelhança destacada é que, durante o diálogo, os animais persuadem os humanos com frases interrogativas (Gn 3,1 e Nm 22,28) que não são respondidas com afirmações ou negações, antes, necessitam de respostas explicativas ${ }^{13}$.

A quinta semelhança é o fato de YHWH ser o doador das falas e visões dos personagens. Em Gn 3, a serpente usa esse "dom" para a perversão e em Nm 22,22-35 para "ajudar" Balaão ${ }^{14}$.

A sexta semelhança é com relação à fala dos animais: ambas levam seus interlocutores para o caminho errado - a serpente leva Eva a errar e, conseqüentemente, a morte, e a mula leva Balaão à vida, pois o leva para longe do anjo ${ }^{15}$.

A sétima semelhança é que os animais têm uma profunda compreensão do relacionamento entre os homens e a divindade. Assim, seus diálogos funcionam pedagogicamente para os homens ${ }^{16}$.

A oitava semelhança entre as narrativas apontadas por Savran está na conclusão das histórias: após a conversa entre o homem e o animal, desejos de dominações são demonstrados. Em Gn 3, as maldições são proferidas diretamente pela divindade sobre o homem, a mulher, a serpente e a natureza, todos os elementos participativos do bloco de Gn 2-3. Já em Nm, o desejo de Balaque de amaldiçoar e dominar sobre Israel, a partir das palavras proferidas por Balaão é frustrado ${ }^{17}$.

\subsection{Novas semelhanças entre Gn 2-3 e Nm 22-24}

As semelhanças apontadas por Savran são convites para a localização de novos pontos de analogia entre as duas narrativas. Ao todo, seis novos tópicos de aproximação podem ser apontados entre Gn 2-3 e Nm 22-24.

${ }^{11}$ SAVRAN, G., op. cit., p. 37-38.

${ }^{12}$ SAVRAN, G., op. cit., p. 38.

${ }^{13}$ SAVRAN, G., op. cit., p. 38-39.

${ }^{14}$ SAVRAN, G., op. cit., p. 39-40.

${ }^{15}$ SAVRAN, G., op. cit., p. 40.

${ }^{16}$ SAVRAN, G., op. cit., p. 40.

${ }^{17}$ SAVRAN, G., op. cit., p. 41. 
A primeira semelhança entre as passagens é a localização canônica dos textos no conjunto do Pentateuco. Levando-se em consideração que Deuteronômio é o livro que faz a transição entre o Pentateuco e a Obra Histórica Deuteronomista, tem-se um Tetrateuco narrativo (Gn, Ex. Lv e Nm) onde Gn 1,3-5 poderia ser lido como um "conto fabuloso" de abertura e Nm 22,22-35 como um "conto fabuloso" de fechamento da Torah. Graficamente, se teria:

\begin{tabular}{|c|c|c|c|}
\hline Gênesis & Êxodo & Levítico & Números \\
\hline $\begin{array}{c}\text { Gn 3,1-5: } \\
\text { conto fabuloso" } \\
\text { de abertura. }\end{array}$ & $\begin{array}{c}\text { Tradições do Êxodo, Tradições do } \\
\text { Deserto e Tradições Legais. }\end{array}$ & $\begin{array}{c}\text { Nm 22,22-35: } \\
\text { "conto fabuloso" } \\
\text { de fechamento. }\end{array}$ \\
\hline
\end{tabular}

Ampliando o gráfico acima e recordando o esquema feito por Zenger para expor a narratologia da Torah, onde diz que "no nível narrativo, o Pentateuco também pode ser lido como o caminho dramático de Israel para a terra da promessa", teria-se ${ }^{18}$ :

\begin{tabular}{|c|c|c|c|}
\hline Gênesis & Exxodo & Levítico & Números \\
\hline $\begin{array}{c}\text { Criação e pro- } \\
\text { messa da terra. }\end{array}$ & & & $\begin{array}{c}\text { Do Sinai pelo } \\
\text { deserto a Moab (à } \\
\text { divisa da terra } \\
\text { prometida. }\end{array}$ \\
$\begin{array}{c}\text { Go Egito pelo } \\
\text { Gn 3,1-5: } \\
\text { dento fabuloso" } \\
\text { de abertura. }\end{array}$ & & No Sinai. & $\begin{array}{c}\text { Nm 22,22-35: } \\
\text { "conto fabuloso" } \\
\text { de fechamento. }\end{array}$ \\
\hline
\end{tabular}

Como demonstrado acima, comparando-se as duas passagens no esquema macro do Pentateuco, pode-se perceber que ele é aberto por um "conto fabuloso" no qual a humanidade, desde a sua criação, é amaldiçoada (Gn $3,1-5)$ e é fechado por um "conto fabuloso" onde Israel é protegido dessa maldição generalizada (Nm 22,22-25).

$\mathrm{Na}$ história de Balaão (Nm 22-24) Israel é sempre abençoado (22,12; 23,7-10; 23,20-24 e 24,5-7) e preservado da maldição de Gn 3. Por outro lado, os inimigos de Israel eleito são maldiçoados (Nm 24,17-24), permanecendo sob a maldição de Gn 3,14-19.

Mais interessante fica a macroestrutura levando-se em consideração que a parte dialogal de Gn 3,1-5 é responsável pela maldição proferida sobre

${ }^{18}$ ZENGER, Erich, Introdução ao antigo Testamento, São Paulo, Loyola, 2003, p. 48. 
tudo e todos (Gn 3,14-19). O diálogo entre Eva e uma serpente é o estopim para que a desobediência "entrasse no mundo", trazendo a maldição como conseqüência (Gn 3,14-19). Contrapondo-se a isso, o diálogo entre Balaão e sua mula é o episódio que resgata a obediência perdida dos primórdios, através do alerta ao profeta para que ele fale apenas o que lhe será ordenado $(\mathrm{Nm} 22,35)^{19}$. Graficamente, se teria:

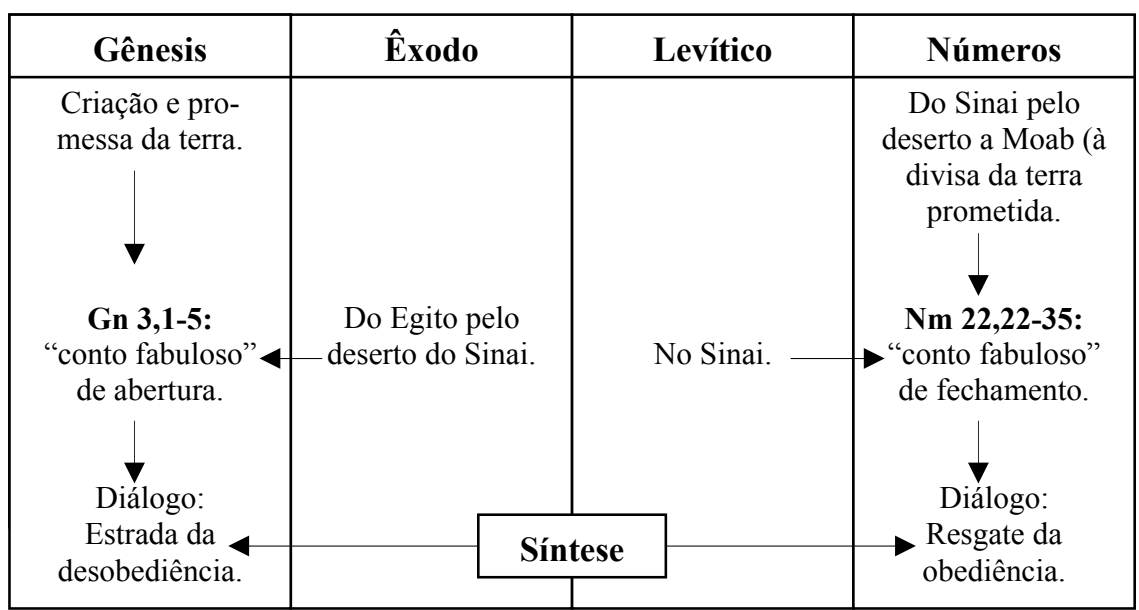

Assim como pelo diálogo com um animal astuto, a serpente, (Gn 3,1) a desobediência entrou no mundo, pela mesma via dialogal, agora com um animal estúpido, a mula, a obediência retorna.

A segunda semelhança entre Gn 3,1-6 e Nm 22,22-35 é com relação às personagens e seu posicionamento em cena. As personagens envolvidas no diálogo ficam sozinhas em cena, enquanto os outros personagens do relato somem momentaneamente, só reaparecendo quando o diálogo já chegou ao fim.

O texto Gn 3,1-6 tem como limite anterior Gn 2,18-25 onde é descrita a formação da mulher. Essa passagem chega ao seu termo com três personagens: YHWH, o homem e a mulher. Entretanto, em Gn 3,1-5 apenas a mulher está em cena, conversando com a serpente. A participação do homem e de YHWH se dão posteriormente, respectivamente nos v. 6 e v. $7 \mathrm{ss}$.

$\mathrm{O}$ mesmo ocorre em $\mathrm{Nm}$ 22,22-35, que tem seu limite anterior em $\mathrm{Nm}$ 22,2-21, cena onde Balaão levantando-se pela manhã, sela sua jumenta e parte com os príncipes de Moab para encontrar com Balaque $(\mathrm{Nm} 22,21)$ e é

\footnotetext{
${ }^{19}$ Para uma melhor compreensão sobre Balaão, como um profeta fiel a YHWH, conf. AKIL, Teresa, "Balaão, o obediente - A imagem de Balaão a partir de uma nova leitura de $\mathrm{Nm}$ 22,2-24,25”, Atualidade Teológica, Rio de Janeiro, ano X, facs. 23, 2006, p. 249-264.
} 
interceptado pelo anjo de YHWH (Nm 22,22-27). Após o diálogo ( $\mathrm{Nm}$ 22,28-31), onde figuram apenas Balaão e a mula, voltam à cena o anjo de YHWH (Nm 22,32ss) e os príncipes de Balaque (Nm 22,35).

Diante dessas observações, se teria uma semelhança de estrutura quiástica quanto ao posicionamento dos personagens nas tramas:

\begin{tabular}{|c|c|}
\hline Gênesis & Números \\
\hline Gn 2,18-25: YHWH, homem e \\
mulher & Nm 22,2-21: Balaque, Mensageiros ${ }^{20} \mathrm{e}$ \\
Balaão \\
Gn 3,1-5: Eva e a Serpente & Nm 22,28-31: Balaão e a Mula \\
Gn 3,6-23: YHWH, homem e mulher & Nm 22,35: Balaque, Mensageiros e \\
& Balaão \\
\hline
\end{tabular}

Por enquanto apontou-se uma primeira semelhança entre Gn 3,1-6 e Nm 22,21-35 na localização canônica das narrativas (estrutura externa), depois apontou-se uma segunda nova semelhança na localização dos personagens na narrativa (estrutura interna) e agora, apresentar-se-ão quatro novas semelhanças concernentes ao tema (através de paralelos léxicos) na seqüência narrativa e conceitos/motivos teológicos.

Analisando os textos quando ao tema na seqüência narrativa, tem-se terceira semelhança entre as histórias de Gn 3,1-6 e Nm 22,22-35. Nas duas narrativas, após conversarem com os animais, os seres humanos "têm seus olhos abertos" e conseguem "ver a dimensão espiritual":

Gn 3,6-7: Então, vendo a mulher que aquela árvore era boa para se comer, e agradável aos olhos, e árvore desejável para dar entendimento, tomou do fruto, comeu, e deu a seu marido, e ele também comeu. Então foram abertos os olhos de ambos e conheceram que estavam nus; pelo que coseram folhas de figueira e fizeram para si aventais.

\section{Nm 22,31: E descobriu Javé o olho de Bil am e viu o mensageiro de Javé parado no caminho e sua espada de- sembainhada em sua mão e inclinou-se e prostou-se em direção às narinas dele.}

Em Gn 3,7 o verbo utilizado é "abrir os olhos" (paqah), enquanto que em Nm 22,31 é "descobrir" (galah). É interessante notar que, apesar de possuírem raízes diferentes, esses verbos apontam para uma mesma direção. $\mathrm{O}$

\footnotetext{
${ }^{20} \mathrm{Na}$ passagem de $\mathrm{Nm}$ 22,2-22 estão em cena tanto mensageiros de Balaque (v. 5.7.15.21) e como o mensageiro de YHWH (v. 22).
} 
verbo no Nifal de Gn 3,7 leva o leitor a entender que ao comer do fruto, os homens tiveram seus olhos abertos por alguém. Já o verbo de Nm 22,31 está no Piel, onde assume o significado de "fazer saber, mostrar e revelar", e deixa explicito que foi YHWH quem revelou algo a Balaão.

Através desta análise verbal, o leitor pode perceber que nas duas histórias YHWH é o agente de $\mathrm{Gn}$ 3,7 e Nm 22,32. É ele quem abre os olhos dos homens. E mais, é também ele quem permite que os homens vejam a esfera do divino e compreendam toda a situação vivenciada.

A quarta semelhança ainda está relacionada à seqüência narrativa: ambas as passagens contam com seres angelicais enviados por YHWH. Em Gn 3,24, querubins são colocados por YHWH em frente ao jardim de Éden e em Nm 22,22-35 o anjo de YHWH aparece a Balaão quando ele ia para a terra de Moab (Nm 22,22). Além de serem enviados por YHWH, esses seres angelicais têm em comum o fato de aparecerem nas passagens ligadas a uma espada (Gn 3,24 e Nm 22,23-31).

Quanto à função na narrativa, os seres angelicais funcionavam como um sinal que deixaria o homem em permanente estado de vigia. Em Gn 3,24 o querubim vigiava, guardava o caminho da árvore da vida para que o homem não conseguisse comer do seu fruto. $\mathrm{O}$ anjo de $\mathrm{Nm}$ 22,22-35 serviu para deixar Balaão em permanente estado de vigia, para que ele só falasse a Balaque o que YHWH ordenasse (Nm 22,35).

Ainda analisando a seqüência narrativa, encontra-se uma quinta semelhança na conclusão das histórias: após a conversa entre o homem e o animal, maldições são proferidas direta ou indiretamente pela divindade as outras personagens que participam da história. Em Gn 3, as maldições são proferidas diretamente pela divindade sobre o homem, a mulher, a serpente e a natureza, todos os elementos participativos do bloco de Gn 2-3. Já em Nm, as maldições são proferidas por Balaão - que fala como mensageiro de YHWH - em seus oráculos contra os povos inimigos de Israel (Nm 24).

A sexta semelhança está na tradição perpetuada pelos episódios. Tanto em Nm 22,22-35 como em Gn 3,1-5, os personagens principais têm suas imagens desmoralizadas para o leitor atual. O diálogo com a serpente resultou na associação de Eva como a "pecadora original", ela "cedeu à tentação" e comeu do fruto, desobedecendo a YHWH.

Já a mula foi quem marcou a história de Balaão, transformando-o para a tradição num profeta cego, que não conseguia ver nem o que sua mula viu. 


\section{As diferenças entre Gn 2-3 e Nm 22-24}

Retornando ao texto de Savran, após elencar as semelhanças ele aponta algumas diferenças entre $\mathrm{Gn}$ 2-3 e Nm 22-24. A primeira é que em Gn 3,1 a pergunta da serpente serve para trazer dúvida à mulher, enquanto que a de Balaão serve para esclarecer uma situação ${ }^{21}$. Segunda, enquanto em Gn 3 a conseqüência da conversa com o animal (Gn 3,14-19) é o estabelecimento da inimizade entre homens-natureza, a expulsão do homem do local da divindade e a vivência sem proteção: em Nm 22-24, a conseqüência é o livramento e a proteção de Deus dispensada a Israel ${ }^{22}$. Terceira, enquanto em Gn 3 a obediência a voz da serpente é a rejeição da autoridade, em Nm 22,2-35, ouvir a voz do anjo é cumprir a vontade de Deus e sujeitar-se a sua autoridade (22$35)^{23}$. A serpente é o protótipo da insubmissão; e a mula, da submissão a $\mathrm{YHWH}^{24}$.

\subsection{As novas diferenças entre $\mathrm{Gn}$ 2-3 e Nm 22-24}

Além dessas diferenças, três novas podem ser encontradas entre Gn 23 e Nm 22-24. A primeira diferença é com relação à figura angelical. O querubim de Gn 3 é mudo, não interage com os personagens, diferente do de Nm 22, que trava um diálogo com Balaão (22,23-35):

v. 32 E disse para ele o mensageiro de Javé: Porque golpeaste a tua mula esta terceira vez. Eis eu saí para resistir, pois se precipitou (lançou) no caminho contra mim.

v. 33 E me viu a mula e desviou-se de diante de mim esta terceira vez, todavia desviou de diante de mim porque agora também a ela matei e a ela deixei viver.

A segunda diferença que deve ser destacada em Gn 3,1-6 e Nm 22,2235 é que, enquanto em Gn 3 a serpente é tida como o animal mais astuto criado por Javé e a responsável indireta pela indução da primeira transgressão humana, em Nm 22, a mula é fiel e sincera serviçal de Balaão, que nunca agiu com teimosia e rebeldia para com seu proprietário.

A terceira diferença é que enquanto a serpente de Gn 3 conduz Eva à transgressão e à rebeldia para com YHWH, em Nm 22,22-31 é a mula de

\footnotetext{
${ }^{21}$ SAVRAN, G., op. cit., p. 38-39

${ }^{22}$ SAVRAN, G., op. cit., p. 41

${ }^{23}$ SAVRAN, G., op. cit., p. 49-50

${ }^{24}$ SAVRAN, G., op. cit., p. 51
} 
Balaão o conduz a realizar a vontade de YHWH, ouvindo o conselho do ser angelical que, mais uma vez, o adverte a falar apenas o que the for ordenado (Nm 22,35).

\section{Conclusão}

As seis novas semelhanças e as três novas diferenças apontadas aqui entre Gn 2-3 e Nm 22-24 vêm corroborar com as palavras de Susan Graham: Leituras intertextuais são verdadeiras janelas, que se abrem tanto na superfície textual (leia-se nos elementos semânticos) como na profundidade textual (ou no aspecto sintáxico). E como textos são feitos de leitores e pelos olhos destes ganham vida, certamente, em novas leituras, novas janelas serão abertas.

Concluindo este artigo, coloca diante dos leitores o desafio de tentar entender qual a finalidade última do escritor sagrado ao colocar as histórias de Eva e da serpente e a de Balaão e sua mula na posição que hoje se encontram, respectivamente, abrindo e fechando o Tetrateuco. Eva abre a janela para a desobediência - "viu que a árvore era boa para se comer, e agradável aos olhos, e árvore desejável para dar entendimento, tomou do fruto, comeu, e deu a seu marido, e ele também comeu" -, Balaão abre a janela para a obediência - "só a palavra que Deus falar, falarei".

Abrir e fechar janelas. Começar e terminar histórias. Essa pode ser a moral contrastante desses contos, em todos os sentidos, fabulosos: podemos começar nossa história em desobediência, mas não devemos assim finalizála.

Teresa Kalil

Doutoranda em Teologia Bíblica pela PUC-Rio

\section{Referências Bibliográficas}

AKIL, Teresa, "Balaão, o obediente - A imagem de Balaão a partir de uma nova leitura de $\mathrm{Nm}$ 22,2-24,25". Atualidade Teológica, Rio de Janeiro, ano X, fasc. 23, 2006, p. 249-264.

ALLEN, Ghahan, Intertextuality (The New Critical Idiom), London, Routledge, 2000.

BAKTHN, Michail, Questões de Literatura e Estética - A teoria do romance, $3^{\text {a }}$ ed., São Paulo, UNESP, 1993. 
FEWELL, Danna Nolan (ed.), Reading Between Texts: Intertextuality and the Hebrew Bible (Literary Currents in Biblical Interpretation), Louisville, Westminster/John Knox Press, 1992.

GRAHAM, Susan, "Intertextual Trekking: Visiting the Iniquity of the Fathers Upon the Next Generation" Semeia 69/70 - Intertextuality and The Bible, January, 1995.

KRISTEVA, Julia, Introdução à semanálise, Trad. Lúcia Helena França Ferraz, São Paulo, Perspectiva, 2005.

ORR, Mary, Intertextuality: Debates and Contexts, Cambridge, Polity Press, 2003.

PENHANSKY, David, Staying the Nigth: Intertextuality in Genesis and Judges, In: FEWELL, Dannna Nolan (ed.), Reading Between Texts: Intertextuality and the Hebrew Bible (Literary Currents in Biblical Interpretation, Louisville, Westminster/John Knox Press, 1992.

PINEDA CACHERO, Antonio, "Comunicación e Intertextualidad en El cuarto de atras", de Carmen Martin Gaite ( $1^{\text {a }}$ parte): literatura versus propaganda, Revista Especulo, Madri, n. ${ }^{\circ}$ 16, nov.2000/fev.2001, Disponível em: http://www.ucm.es/info/especulo/numero16/pineda1.html, Acesso em 16 ago.2006.

SAVRAN, G., "Beastly Speech:Intertextualy, Ballam's Ass and the Garden of Eden", Journal of the Study of the Old Testament, Jerusalem, n. ${ }^{\circ}$ 64, p. 1-40, 1994.

VIGNER, Gerard, Intertextualidade, norma e legibilidade, In: GALVES, Charlotte; ORLANDI, Eni P. \& OTONI, Paulo, O texto, leitura e escrita, Campinas, Pontes, 1997.

ZENGER, Erich, Introdução ao Antigo Testamento, São Paulo, Loyola, 2003. 